\title{
THE LOSS OF SMELL (ANOSMIA) IN COVID 19 PATIENTS-TO WHAT EXTENT IT HELPS IN THE DIAGNOSIS OF COVID 19 AND FACTORS INFLUENCING ITS RECOVERY-A CLINICAL STUDY
}

\author{
V SANJEEV UDAY SRIKAR ${ }^{1}$, YELLETI VENKATA NAGA SWARNA², GANDUPALLI YUGANDHAR ${ }^{1 *}$
}

${ }^{1}$ Department of ENT, GITAM Institute of Medical Sciences and Research, GITAM Deemed to be University, Visakhapatnam, Andhra Pradesh, India. ${ }^{2}$ Department of ENT, Rangaraya Medical College, Kakinada, Andhra Pradesh, India. Email: yugandhar0909@gmail.com

Received: 11 December 2021, Revised and Accepted: 18 January 2022

\section{ABSTRACT}

Objectives: COVID-19 outbreak is a major pandemic affecting many people worldwide, including India. The main clinical features of this disease are cough, fever, and myalgia, and in some cases, breathing difficulty. There are many non-specific symptoms also. Loss of smell (Anosmia) is one of the non-specific clinical features in many patients. The main objective of this study is to diagnose COVID-19 disease in patients presenting with loss of smell, which helps in early isolation of the patient and prevents the spread of infection to others before the diagnosis of COVID-19 is confirmed by RTPCR, which may take 2-3 days. Another objective of this study is to know the factors that influence recovery from anosmia.

Methods: Data was collected from 105 patients who attended Outpatient Department/COVID Ward in GITAM Institute of Medical Sciences and Research, Rushikonda, Visakhapatnam, from April 2020 to August 2020. The follow-up study for factors influencing the recovery of anosmia was performed in 100 patients who tested positive for COVID-19 disease with loss of smell as a presenting feature.

Results: Male, to female ratio of patients with upper respiratory infection and loss of smell was 64:36. Out of 105 patients, 27 were tested positive for COVID19. Thus, the prevalence of anosmia in COVID 19 patients was 28.35\%. In the follow-up study, out of 100 patients, 34 patients showed complete recovery in 2 weeks, and 42 patients showed partial recovery in 2 weeks and complete recovery in 4 weeks, and 24 patients showed only partial or no recovery within 1 month from the onset of anosmia.

Conclusions: The presence of anosmia can be considered as a non-specific clinical feature in COVID-19, and early identification and isolation of the patient will help in decreasing the spread of disease to other people before the COVID-19 diagnosis is confirmed. It also suggests that recovery from loss of smell is better in middle-aged and female patients. The recovery has been delayed in patients with comorbidities and older people.

Keywords: COVID-19, Loss of smell, Anosmia, Outpatient Department patients and Recovery of anosmia.

(c) 2022 The Authors. Published by Innovare Academic Sciences Pvt Ltd. This is an open access article under the CC BY license (http://creativecommons.org/ licenses/by/4.0/) DOI: http://dx.doi.org/10.22159/ajpcr.2022v15i2.43872. Journal homepage: https://innovareacademics.in/journals/index.php/ajpcr

\section{INTRODUCTION}

In December 2019, Pneumonia cases were identified in Hubei Province in China [1]. The disease was caused by Novel Coronavirus, and later the disease omit was spread to the entire world and declared as a pandemic by the WHO [2]. In India, the first case of COVID-19 was identified in Kerala on January 30, 2020 [3]. As per the WHO dashboard on November 8,2020 , the total cases were 4.95 crores, and in India the total cases were 85 lakhs. In COVID-19 patients, the main manifestations were fever and cough and characterized by lymphocytopenia and ground-glass opacity changes on chest computed tomography. Patients often presented without fever, and many did not have abnormal radiological findings $[4,5]$. Besides, some patients presented with the upper respiratory symptoms such as pharyngodynia, sore throat, nasal congestion, rhinorrhea, and olfaction alterations [6,7]. Patients with COVID-19 reported a wide variety of clinical manifestations, from mild symptoms, such as fever and cough, to severe symptoms, such as shortness of breath, arrhythmia, and loss of consciousness [8,9]. Many non-specific symptoms were also present in some part of patients; the presence of olfactory dysfunction, such as loss of smell (Anosmia), was one of the non-specific clinical features. Patients with COVID-19 infection can present a sudden onset of anosmia without any other symptoms $[10,11]$. Before the beginning of anosmia, other mild symptoms such as a dry cough may also be present [12]. Coronavirus is known to cause loss of smell and other signs of upper respiratory infection (URI). This study aims to diagnose COVID-19 disease in patients presenting with loss of smell, which helps in early isolation of the patient and prevents the spread of disease to others before the diagnosis of COVID-19 confirmed by RTPCR, which may take 2-3 days. Another aim of the study is to know the factors that influence recovery from anosmia. Recent studies have identified that sudden loss of smell (Anosmia) and loss of taste was also significant symptoms in COVID19 infection [13]. These symptoms were found even in patients with no other symptoms/signs of URI. Unlike the other viral infection, the loss of smell in the COVID-19 infection is characteristic as it is not associated with rhinorrhea or any other nasal symptoms. The treatment given to all the patients was [14] Doxycycline 100 mg BD for 5 days, Ivermectin $12 \mathrm{mg}$ OD for 3 days, Montek LC OD for 5 days, Vitamin C OD for 10 days, nasal saline irrigation, topical nasal steroids, steam inhalation, multivitamins, and high protein diet.

\section{METHODS}

Data was collected from 105 patients who attended the Outpatient Department (OPD)/COVID ward in GITAM Institute of Medical Sciences and Research, Visakhapatnam, from the month of April 2020 to August 2020.

The follow-up study for factors that influence the recovery of anosmia was performed in 100 patients who tested positive for COVID-19 disease with loss of smell as one of the presenting features. Most of these patients went to home isolation and took the treatment, and few of them were admitted to various COVID hospitals in Visakhapatnam. These patients were followed up by regular telephonic conversation.

\section{Inclusion criteria}

All the patients between the age group of 20 and 65 years who came to the OPD/COVID-19 ward with clinical features suggestive of upper respiratory tract infections URI along with loss of smell were included in this study. 


\section{Exclusion criteria}

Patients who underwent nasal surgeries and suffering from nasal allergies and known cases of sinusitis were excluded from the study.

Statistical analysis

The statistical tests used in this study are the test of proportion and percentage.

\section{RESULTS}

Data was collected from 105 patients who attended OPD/COVID 19 ward from GIMSR hospital. Among the 105 patients, 67 patients were males and 38 were females. The male to female ratio of patients with URI and loss of smell was 64:36. Out of 105 patients, 27 were tested positive for COVID-19 (Fig. 1). Thus, the prevalence of anosmia in COVID 19 patients was $28.35 \%$. Out of 27 COVID positive patients, only 9 patients were admitted to various COVID hospitals and took treatment, and the rest of the 18 patients took medication with home isolation only. All 9 patients were discharged after the COVID19 negative result at 14 days. After 14 days, 18 patients had regained their sense of smell. All the patients who were not in follow-up were contacted by telephone at the end of 3 weeks, and all the patients had regained the sense of smell. In the follow-up study, out of 100 patients, 34 patients showed complete recovery in 2 weeks, and 42 patients showed partial recovery in 2 weeks and complete recovery in 4 weeks, and 24 patients showed only partial or no recovery within 1 month from the onset of anosmia (Fig. 2).

\section{DISCUSSION}

The COVID-19 outbreak is a major pandemic affecting many people worldwide, including India. Fever and respiratory signs and symptoms are established clinical features of this disease. Most of the clinical features are atypical; loss of smell (Anosmia) is one of the atypical features. Viral URI is a known cause of olfactory dysfunction. Based on the present meta-analysis of available data, the presence

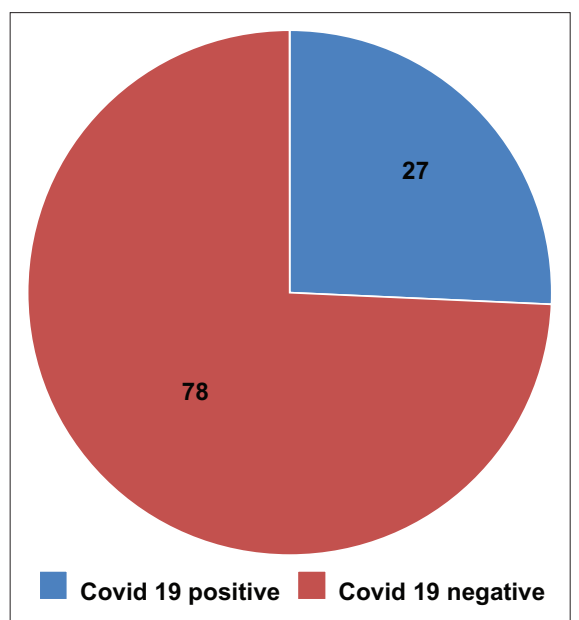

Fig. 1: Prevalence of anosmia in patients who were tested COVID positive

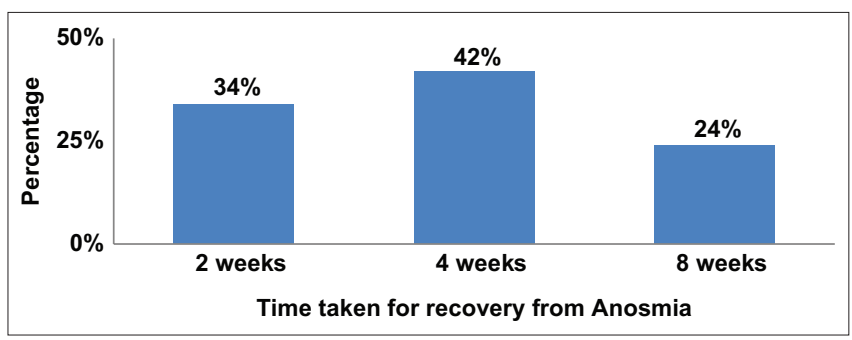

Fig. 2: Time taken for recovery from anosmia of anosmia/hyposmia seems to be associated with an enhanced risk of testing positive for COVID-19. Several reasons can be proposed to explain this result. First, Angiotensin-Converting Enzyme 2 (ACE2), the receptor for SARS-CoV-2, the pathogen causing COVID-19 infection, is expressed in the nasal mucosa. The virus can enter the nasal mucosa through ACE2 and cause damage to the supporting cells of the olfactory system, such as the olfactory epithelium sustentacular cells, microvillar cells, Bowman gland cells, horizontal basal cells, and olfactory bulb pericytes. These damages can alter the function of the olfactory neurons, contributing to the development of symptoms of olfactory dysfunction [15]. Another possible mechanism is the inflammatory blockage of the olfactory cleft in the COVID-19 infection, which contributes to the development of anosmia [16]. Finally, it has been found that the sinonasal route is an important area of COVID-19 viral shedding; therefore, the presence of olfactory dysfunction may reflect the reality of infection and the early course of the disease [17]. A recent study by Sungnak et al. [18] suggested that nasal epithelial cells show a high ACE2 expression in SARS-CoV-2 infection, and thus this may allow wide viral entry. A retrospective study by Klopfenstein et al. 54 (47\%) out of 114 confirmed COVID-19 patients presented with anosmia [19]. This anosmia can be a possible atypical feature in COVID 19 patients. In our present study, 105 patients who attended OPD with an URI with loss of smell were tested for COVID 19, among which 27 were tested positive $(28.35 \%)$. Thus, the prevalence of anosmia inpatient with URI can be considered a non-specific clinical feature in COVID-19. In the follow-up study of 100 patients, 34 patients showed complete recovery in 2 weeks, and 42 patients showed partial recovery in 2 weeks and full recovery in 4 weeks, and 24 patients showed only partial or no recovery within 1 month from the onset of anosmia. According to Klopfenstein et al., $98 \%$ of patients could recover within 28 days [19]. It suggests that recovery from loss of smell is better in middle-aged and female patients, and the process has been delayed in patients with co-morbidities and older people. Furthermore, most studies have found that smell disorders in COVID-19 patients are higher in females than males [20-22]. The characteristic of female preponderance is consistent with the findings of previous studies about the OD caused by URI [23]. On March 21, Prof Claire Hopkins, President of the British Rhinological Society, first officially emphasized anosmia as a common early symptom of COVID-19 infection. On March 26, the American academy of otolaryngologyhead and neck surgery released a statement noting that anosmia with dysgeusia is associated with the COVID-19 patients. The academy has also established the COVID-19 Anosmia Reporting Tool, an online questionnaire for patients globally to submit data. On April 17, CDC summarized and updated the most common symptoms of COVID-19, adding "new loss of taste or smell" to the list of symptoms [24].

\section{CONCLUSIONS}

The presence of anosmia can be considered as a non-specific clinical feature in COVID-19, and early identification and isolation of the patient will help in decreasing the spread of disease to other people before the COVID-19 is confirmed. It also suggests that the recovery from loss of smell is better in middle-aged and female patients, and the process has been delayed in patients with comorbidities and the elderly.

\section{AUTHORS' CONTRIBUTION}

The principal author of the study, US, had performed the research work. The Co-authors of the study, GY, wrote the first draft of the manuscript, collected the literature and NS performed the statistical analysis part of the work and corrected the final draft of the manuscript.

\section{CONFLICT OF INTEREST}

There is no conflict of interest.

\section{SOURCE OF FUNDING}

The study was not supported by any grants and funds. 


\section{REFERENCES}

1. Huang C, Wang Y, Li X, Ren L, Zhao J, Hu Y, Zhang L, et al. Clinical features of patients infected with 2019 novel Coronavirus in Wuhan, China. Lancet 2020;395:497-506.

2. Cucinotta D, Vanelli M. WHO declares COVID-19 a pandemic. Acta Biomed 2020;91:157-60.

3. Andrews MA, Areekal B, Rajesh KR, Krishnan J, Suryakala R, Krishnan B, et al. First confirmed case of COVID-19 infection in India: A case report. Indian J Med Res 2020;151:490-2.

4. Abbasi-Oshaghi E, Mirzaei F, Farahani F, Khodadadi I, Tayebinia H. Diagnosis and treatment of Coronavirus disease 2019 (COVID-19): Laboratory, PCR, and chest CT imaging findings. Int J Surg 2020;79:143-53

5. Guan WJ, Ni ZY, Hu Y, Liang WH, Ou CQ, He JX. Clinical characteristics of Coronavirus disease 2019 in China. N Engl J Med 2020;382:1708-20

6. Lovato A, de Filippis C, Marioni G. Upper airway symptoms in Coronavirus disease 2019 (COVID-19). Am J Otolaryngol 2020;41:102474.

7. Lovato A, de Filippis C. Clinical presentation of COVID-19: A systematic review focusing on upper airway symptoms. Ear Nose Throat J 2020;99:569-76.

8. Yang W, Cao Q, Qin L, Wang X, Cheng Z, Pan A, et al. Clinical characteristics and imaging manifestations of the 2019 novel Coronavirus disease (COVID-19): A multi-center study in Wenzhou city, Zhejiang, China. J Infect 2020;80:388-93.

9. Kwenandar F, Japan VK, Damay V, Hariyanto TI, Tanaka M, Lugito NPH, et al. Coronavirus disease 2019 and cardiovascular system: A narrative review. Int J Cardiol Heart Vasc 2020;29:100557.

10. Heidari F, Karimi E, Firouzifar M, Khamushian P, Ansari R, Ardehali Mm. Anosmia as a prominent symptom of COVID-19 infection. Rhinology 2020;58:302-3.

11. Gane SB, Kelly C, Hopkins C. Isolated sudden onset anosmia in COVID-19 infection. A novel syndrome? Rhinology 2020;58:299-301.

12. Eliezer M, Hautefort C, Hamel A, Verillaud B, Herman P, Houdart E, et al. Sudden and complete olfactory loss of function as a possible symptom of COVID-19. JAMA Otolaryngol Head Neck Surg 2020;146:674-5
13. Lechien JR, Chiesa-Estomba CM, De Siati DR, Horoi M, Le Bon SD, Rodriguez A, et al. Olfactory and gustatory dysfunctions as a clinical presentation of mild-to-moderate forms of the Coronavirus disease (COVID-19): A multicenter European study. Eur Arch Otorhinolaryngol 2020;277:2251-61

14. Yates PA, Newman SA, Oshry LJ, Glassman RH, Leone AM, Reichel E. Doxycycline treatment of high-risk COVID-19-positive patients with comorbid pulmonary disease. Ther Adv Respir Dis.2020;14:1-5.

15. Vaira LA, Salzano G, Fois AG, Piombino P, De Riu G. Potential pathogenesis of ageusia and anosmia in COVID-19 patients. Int Forum Allergy Rhinol 2020;10:1103-4.

16. Meng X, Deng Y, Dai Z, Meng Z. COVID-19 and anosmia: A review based on up-to-date knowledge. Am J Otolaryngol 2020;41:102581.

17. Gengler I, Wang JC, Speth MM, Sedaghat AR. Sinonasal pathophysiology of SARS-CoV-2 and COVID-19: A systematic review of the current evidence. Laryngoscope Investig Otolaryngol 2020;5:354-9.

18. Sungnak W, Huang N, Bécavin C, Berg M, HCA Lung Biological Network. SARS-CoV-2 Entry Genes Are Most Highly Expressed in Nasal Goblet and Ciliated Cells within Human Airways, ArXiv; 2020.

19. Klopfenstein T, Kadiane-Oussou NJ, Toko L, Royer PY, Lepiller Q, Gendrin V, et al. Features of anosmia in COVID-19. Med Mal Infect 2020;50:436-9.

20. Giacomelli A, Pezzati L, Conti F, Bernacchia D, Siano M, Oren L, et al. Self-reported olfactory and taste disorders in patients with severe acute respiratory coronavirus 2 infection: A cross-sectional study. Clin Infect Dis 2020;71:889-90.

21. Bagheri SH, Asghari A, Farhadi M, Shamshiri AR, Kabir A, Kamrava SK, et al. Coincidence of COVID-19 epidemic and olfactory dysfunction outbreak in Iran. Med J Islam Repub Iran 2020;34:62.

22. Spinato G, Fabbris C, Polesel J, Cazador D, Borsetto D, Hopkins C. Alterations in smell or taste in mildly symptomatic outpatients with SARS-CoV-2 infection. JAMA 2020;323:2089-90.

23. Jafek BW, Murrow B, Michaels R, Restrepo D, Linschoten M. Biopsies of human olfactory epithelium. Chem Senses 2002;27:623-8.

24. Kaye R, Chang CW, Kazahaya K, Brereton J, Denneny JC $3^{\text {rd }}$. COVID-19 anosmia reporting tool: Initial findings. Otolaryngol Head Neck Surg 2020;163:132-4. 